SHORT REPORT

\title{
Urinary catecholamines and metabolites in the immediate postoperative period following major surgery
}

\author{
Dr A A Syed, H A Wheatley, M N Badminton, I F W McDowell
}

J Clin Pathol 2004;57:548-550. doi: 10.1136/¡cp.2003.013201

\begin{abstract}
Background: Induction of anaesthesia can precipitate catecholamine release from an undiscovered pheochromocytoma and induce a hypertensive crisis. However, it is assumed that catecholamine and metabolite values resulting from the effects of surgery per se in the early postoperative period would overlap with the values generated by a tumour, and it is not known how soon after biochemical investigations can be carried out.

Aim: To study patterns of urinary catecholamine excretion and the feasibility of biochemical screening for phaeochromocytomas in the immediate postoperative period in otherwise healthy subjects undergoing a single type of major surgical procedure.

Methods: Catecholamines and metabolites were measured for each mole of creatinine in single voided urine on one preoperative and four postoperative days in five subjects who underwent elective coronary artery bypass graft surgery with an uncomplicated postoperative course. Reference ranges were established from 33 healthy normotensive volunteers.

Results: Excretion of adrenaline, noradrenaline, dopamine, vanillylmandelic acid, and metadrenaline was within normal limits. Normetadrenaline excretion was mildly raised in four patients, but did not exceed 1.5 times the upper reference limit, and returned to normality by the fourth postoperative day.

Conclusion: It is feasible to perform simple urinary screening for possible phaeochromocytoma in the immediate postoperative period.
\end{abstract}

\footnotetext{
A
} lthough phaeochromocytomas are rare, accounting for $0.1-1 \%$ of all cases of hypertension, ${ }^{1}$ occasionally, unsuspected cases present with a hypertensive episode during the induction of anaesthesia or surgery for unrelated conditions. ${ }^{2}{ }^{3}$ It would be reasonable, therefore, to screen for catecholamine secreting tumours in surgical patients in whom hypertension is first seen or becomes difficult to control perioperatively. However, a very high false positive rate in the early postoperative period resulting from the effects of surgery per se is generally expected, and it is not known how soon after surgery biochemical screening tests can be reliably performed. The aim of our study was to determine patterns of urinary catecholamine excretion and the feasibility of biochemical screening for phaeochromocytomas in the immediate postoperative period in otherwise healthy subjects undergoing a single type of major surgical procedure.

MATERIALS AND METHODS

We prospectively studied five subjects (four men) ranging in age from 41 to 75 (mean, 54.8) years who underwent elective coronary artery bypass graft surgery. None of them was administered catecholamines as part of their management and all had a routine postoperative recovery. For the purpose of this preliminary study, we monitored urinary catecholamine and metabolite excretion for each mole of creatinine using "spot" urine specimens, because this eliminates sampling errors of timed collections, and has a sensitivity of $97-100 \%$ and a specificity of $98-100 \%{ }^{4-6}$ Midday self voided or fresh catheter urine was obtained on one preoperative (day 0 ) and four postoperative days (days 14 ). Thirty three healthy volunteers ( 14 men, 10 women, nine undeclared sex), ranging in age from 22 to 55 (mean, 35.7) years, with no history of hypertension, served as controls for the determination of reference ranges, and 1.5 times the upper limit was regarded as the threshold of significance. ${ }^{7}$ Samples were acidified with concentrated hydrochloric acid to $\mathrm{pH}<4.0$ immediately (within one hour) after collection. Adrenaline (A), noradrenaline (NA), dopamine (DA), metadrenaline (MA), and normetadrenaline (NMA) were measured using high performance liquid chromatography incorporating sample clean up with automated sample trace enrichment of dialysate coupled with electrochemical detection, ${ }^{8}$ and vanillylmandelic acid (VMA) by gas chromatography of trimethyl silyl derivatives (Pisano reaction). ${ }^{9}$ Creatinine was measured by a kinetic colorimetric assay (Jaffé reaction). ${ }^{10}$ A single determination was performed for all analytes. Our study conformed with the ethical principles of the Declaration of Helsinki (Fifth Amendment) and participants gave their consent.

\section{RESULTS}

A (reference range, $1-20 \mathrm{nmol} / \mathrm{mol}$ creatinine), NA (reference range, $4-185 \mathrm{nmol} / \mathrm{mol}$ creatinine), DA (reference range, $83-643 \mathrm{nmol} / \mathrm{mol}$ creatinine), MA (reference range, 9-681 $\mu \mathrm{mol} / \mathrm{mol}$ creatinine), and VMA (reference range, $0.42-7.27 \mathrm{mmol} / \mathrm{mol}$ creatinine) remained well within their respective reference ranges on all days in all subjects (fig 1 ). Mild increases in NMA (reference range, 5-242 $\mu \mathrm{mol} / \mathrm{mol}$ creatinine), not exceeding 1.5 times the upper reference limit, were seen postoperatively in four patients (patients 1-4) on days $1-3$, returning to normality by day 4 .

\section{DISCUSSION}

We report that catecholamine and metabolite excretion is not significantly increased after major surgery using elective open chest coronary revascularisation as an example. We suggest that this is, at least in part, explained by good perioperative anxiolysis and pain relief achieved by modern anaesthetic techniques. This finding reflects a previous report that circulating plasma catecholamine concentrations do not increase significantly above preanaesthetic values in patients

Abbreviations: $A$, adrenaline; DA, dopamine; $M A$, metadrenaline; NA, noradrenaline; NMA, normetadrenaline; VMA, vanillylmandelic acid 

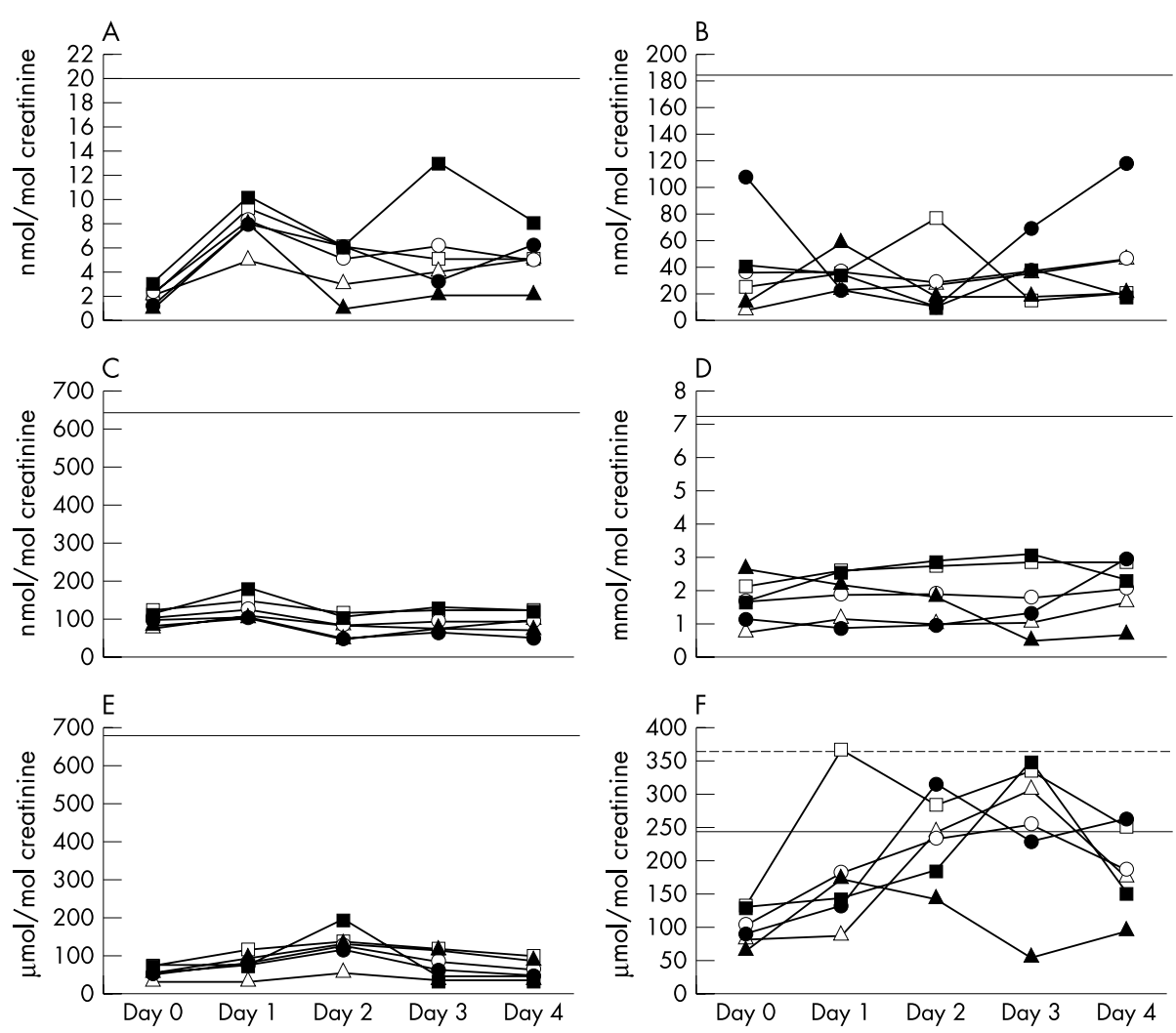

Figure 1 Catecholamines and metabolites expressed for each mole of creatinine in single voided urine specimens on one preoperative (day 0) and four postoperative (days 1-4) days in five patients undergoing coronary artery bypass graft surgery. (A) Adrenaline, (B) noradrenaline, (C) dopamine, (D) vanillylmandelic acid, (E) metadrenaline, (F)

normetadrenaline (NMA). The solid horizontal lines mark the upper limit of the reference range and the broken horizontal lines (NMA) mark 1.5 times the upper limit. Closed circles, patient 1 ; open squares, patient 2; open triangles, patient 3; closed squares, patient 4; closed triangles, patient 5; open circles, mean. undergoing cardiac surgery. ${ }^{11}$ However, no conclusions could be drawn from urinary measurements in that study because analysis was complicated by the finding of a positive correlation between catecholamine excretion and urine flow rate.

Raised concentrations of NA compared with the hypertensive reference range are often seen in patients with hypertension or myocardial infarction treated with $\beta$ blockers. $^{12}{ }^{13}$ The modest rise in NMA excretion in our study could be a reflection of a similarly raised noradrenergic tone, although NA excretion itself was not increased, and may indicate the need for an "adjusted normal range" for postoperative patients.

"The main advantage of urinary screening in this situation is that it facilitates rapid elimination of phaeochromocytoma from the differential diagnosis"

We acknowledge that urinary screening in surgical patients who experience a stormy perioperative course may be associated with a poor positive predictive value. However,

\section{Take home messages}

- Catecholamine and metabolite excretion was not significantly increased after major surgery using elective open chest coronary revascularisation as an example

- Therefore, it seems feasible to perform simple urinary screening for possible phaeochromocytoma in the immediate postoperative period, although a larger study encompassing a wider spectrum of surgical and anaesthetic procedures is required given its very high negative predictive value $(100 \%),{ }^{14}$ the main advantage of urinary screening in this situation is that it facilitates rapid elimination of phaeochromocytoma from the differential diagnosis. Although the small number of subjects, who all had a routine postoperative course, limits the applicability of our study, it has established that the general expectation of false positive results in nearly all surgical patients in the immediate postoperative period is erroneous. In conclusion, we propose that it is feasible to investigate patients for possible phaeochromocytoma in the immediate postoperative period by simple urinary screening, but a larger study encompassing a wider spectrum of surgical and anaesthetic procedures is required.

\section{ACKNOWLEDGEMENTS}

We thank all participants in the study and ward staff for their cooperation.

\section{Authors' affiliations}

A A Syed, H A Wheatley, M N Badminton, I F W McDowell, Department of Medical Biochemistry, University Hospital of Wales, Cardiff CF1 4 4XW, UK

Correspondence to: Dr A A Syed, M4062, Medical Molecular Biology Group, 4th Floor, Cookson Building, Medical School, University of Newcastle, Newcastle upon Tyne, NE2 4HH, UK; a.a.syed@ncl.ac.uk

Accepted for publication 21 November 2003

\section{REFERENCES}

1 Bouloux P-MG. The sympatho-adrenal system, phaeochromocytomas and related tumours. In: Grossman A, ed. Clinical endocrinology. Oxford: Blackwell Science, 1998:497-528.

2 Diamond JA. Pheochromocytoma in a symptomatic patient with severe hypertension upon anesthesia induction. Am J Hypertens 2001;14:729-30.

3 Ehata T, Karasawa F, Watanabe K, et al. Unsuspected pheochromocytoma with abdominal aortic aneurysm-a case report. Acta Anaesthesiol Sin 1999;37:27-8. 
4 Ito $Y$, Obara $T$, Okamoto $T$, et al. Efficacy of single-voided urine metanephrine and normetanephrine assay for diagnosing pheochromocytoma. World J Surg 1998;22:684-8.

5 Jibiki K, Demura H, Naruse M, et al. [Biochemical diagnosis of pheochromocytoma by determining normetanephrine and metanephrine concentrations in single voided urine.] Nippon Naibunpi Gakkai Zasshi 1988;64:707-16.

6 Kaplan NM, Kramer NJ, Holland OB, et al. Single-voided urine metanephrine assays in screening for pheochromocytoma. Arch Intern Med 1977; 137:190-3.

7 Stein PP, Black HR. A simplified diagnostic approach to pheochromocytoma. A review of the literature and report of one institution's experience. Medicine (Baltimore) 1991;70:46-66.

8 Green B, Cooper JD, Turnell DC. An automated method for the analysis of urinary free catecholamines using ASTED and high-pressure liquid chromatography. Ann Clin Biochem 1989;26:361-7.
9 van de Calseyde JF, Scholtis RJ, Schmidt NA, et al. Gas chromatography in the estimation of urinary metanephrines and VMA. Clin Chim Acta 1971;32:361-6.

10 Bartels H, Bohmer M, Heierli C. [Serum creatinine determination without protein precipitation.] Clin Chim Acta 1972;37:193-7.

11 Hine IP, Wood WG, Mainwaring-Burton RW, et al. The adrenergic response to surgery involving cardiopulmonary bypass, as measured by plasma and urinary catecholamine concentrations. Br J Anaesth 1976;48:355-63.

12 Idris IR, Hill R, Sands KA, et al. Retrospective analysis of abnormal 24-h urinary free catecholamine concentration in screening for phaeochromocytoma. Ann Clin Biochem 2003;40:283-5.

13 McGrath B, Arnolda L, Saltups A. The catecholamine response to acute myocardial infarction: effect of early administration of sotalol. Aust N Z J Med 1986; 16:658-64.

14 Heron E, Chatellier G, Billaud E, et al. The urinary metanephrine-to-creatinine ratio for the diagnosis of pheochromocytoma. Ann Intern Med $1996 ; 125: 300-3$. 


\section{PostScript}

\section{CORRESPONDENCE}

If you have a burning desire to respond to a paper published in the Journal of Clinical Pathology, why not make use of our "rapid response" option?

Log on to our website (www.jclinpath. com), find the paper that interests you, and send your response via email by clicking on the "eletters" option in the box at the top right hand corner.

Providing it isn't libellous or obscene, it will be posted within seven days. You can retrieve it by clicking on "read eletters" on our homepage.

The editors will decide as before whether to also publish it in a future paper issue.

\section{Cancer stem cell theory: pathologists' considerations and ruminations about wasting time and wrong evaluations}

The genomic revolution has changed the role of the pathologist. In daily practice, our work is no longer limited to reaching a correct diagnosis and we are asked to answer questions about the patient's prognosis and treatment options through the evaluation of selected molecular targets (such as erbB2 for breast cancer) in tumour specimens. Thus, we have acquired a major role in the translation of novel gene findings from experimental model systems to their clinical application.

There is overwhelming evidence that only a subset of cells within a tumour clone, referred to as cancer stem cells, are tumorigenic and possess the metastatic phenotype. The recent identification of human breast cancer initiating cells by Al-Hajj and colleagues $^{2}$ provided a major step forward in this field. With this knowledge, the stem cell compartment should represent the selected target for tumour eradication.

As pathologists we would like to share some considerations and ruminations about this scenario.

Currently, tissue microarray analysis generates gene profiles capable of differentiating tumours with different biological behaviours. ${ }^{3}$ However, this screening method is conducted on heterogeneous tumour tissue samples containing a mixture of non-neoplastic cells, non-tumorigenic cancer cells, and cancer stem cells. Similarly, until now, we have evaluated the immunohistochemical expression of a molecular marker in the bulk of the tumour, considering it as relatively homogeneous.

What is the clinical relevance of these results? Although new therapeutic approaches based on these studies have modified the prognosis of some neoplasms, ${ }^{4}$ conflicting results are still seen with many other tumours. ${ }^{5}$ We should start to feel worried about the value of the information retrieved from this type of tumour analysis.
The few cancer stem cells and the large number of cells constituting the tumour are morphologically similar but functionally heterogeneous. It is likely that we are still evaluating the main population of tumour cells, which are not cancer stem cells, and are thus probably wasting time and loosing essential treatment information. It is unlikely that gene expression profiles obtained using the currently available methods reflect those of the tumour stem cell population, which forms only $0.1-2 \%$ of the whole tissue sample. ${ }^{126}$

The cancer stem cell hypothesis has started a new era in cancer research. Tumours contain functionally different subpopulations of cells. However, unique gene expression profiles are generated by current methods of evaluation. Probably, when the isolation and molecular characterisation of cancer stem cells from primary tissue becomes possible, the role of pathologists will change again. Collaboration between researchers and pathologists will be more widely practised and we will be able to rise to the next challenge; namely, assessing the prognosis of a patient from only one of 5000 tumour cells in a tissue sample.

P Nuciforo

Fimo-Firc Institute of Molecular Pathology Via Adamello 16, Milano 20139, Italy nuciforo@ifom-firc.it

F Fraggetta

Azienda Ospedaliera Cannizzaro, Via Messina, 829, Catania 95126 , Italy

\section{References}

1 Reya T, Morrison SJ, Clarke MF, et al. Stem cells, cancer, and cancer stem cells. Nature 2001:414:105-11.

2 Al-Haii M, Wicha MS, Benito-Hernandez A, et al. Prospective identification of tumorigenic breast cancer cells. Proc Natl Acad Sci U S A 2003;100:3983-8.

3 Van de Vijuer MJ, He YD, van't Veer $\sqcup$, et al. A gene-expression signature as a predictor of survival in breast cancer. N Engl I Med 2002;347:1999-2009.

4 Orr MS, Scherf U. Large-scale gene expression analysis in molecular target discovery. Leukemia 2002;16:473-7.

5 Carney DN. Lung cancer-time to move on from chemotherapy. N Engl I Med 2002;346:126-8.

6 Dick JH. Breast cancer stem cells revealed. Proc Natl Acad Sci U S A 2003;100:3547-9.

\section{Public opinion on the use of tissue samples}

I read with interest and increasing concern the paper by Goodson and Vernon, " "A study of public opinion on the use of tissue samples from living subjects for clinical research". The paper demonstrates that the use of a vaguely worded and ambiguous questionnaire leads to misleading results. A few of the problems with the questions may be taken individually:

(1) "Would you be happy for pieces of any of the following body tissues or organs to be used in clinical research? (Eyes, lung, heart, tissue from head and neck, embryo, brain, ovary, testes, bone, and breast.)"
The question could refer to postmortem tissue and the choice of organs is (as the authors confess) deliberately "emotional", with no insight into every day pathological services. Heart, brain, and eyes are not exactly common surgical specimens, whereas embryos are subject to special guidelines. Surely, this question is almost designed to make the patient believe it refers to postmortem organs? The use of subjective words such as "happy" is extremely unhelpful. "Are you happy to vote Labour?" would not, for example, be acceptable in a comparable political survey!

(2) "What kind of research would you be happy for your tissues to be used for? (Cancer research, testing medicines, genetic cloning, general knowledge of body tissues, genetic research for diagnosis or treatment of, for example, Down's syndrome.)"

Again scientific imprecision exists, because the writers of the questionnaire appear not to understand that these fields are interdependent. In particular, the lack of public understanding of cloning has caused them to reject this field, with no idea that this may include tissue culture or polymerase chain reaction

(3) "Would you want to be informed if your tissues were to be stored beyond the time required for diagnosis?"

This question seems to show no knowledge of the necessity for longterm storage of samples after diagnosis. Tissue retention for medicolegal, audit, clinical governance, and comparison with later samples has been ignored. No explanation has been given to the patients of why this is in their best interests.

(4) "Would you be happy to give consent for a child's tissues to be used for scientific research?"

Apart from the obvious flaw that it has not been stated whose child is being talked about, again the question appears almost deliberately ambiguous and could be taken to refer to postmortem tissue. Apparently, the designers of the questionnaire are interested in "scientific research" on children's tissues, whereas in adults in question $l$ it is only "clinical research".

(5) "Would you be happy to give consent for your tissues to be used to teach medical students?"

The word happy is used again, in addition to a lack of explanation of how the tissues are "used", and the vital role of histology in teaching medical students and pathology trainees.

I suggest to the authors that their survey, in contrast to all other studies, shows that patients were unwilling to donate their tissues because they were presented with a poorly designed, misleading survey.

D M Berney

Department of Pathology, St Bartholomew's Hospital, West Smithfield, London EClA 7BE, UK; danberney@hotmail.com 


\section{Reference}

1 Goodson ML, Vernon BG. A study of public opinion on the use of tissue samples from living subjects for clinical research. J Clin Pathol 2004:57:135-8.

\section{Authors' response}

We are grateful for the opportunity to respond to Dr Berney's letter. The questionnaire used in our study was piloted on a similar group of respondents. The patient information leaflet and consent form given and explained before completion of the questionnaire made it clear that we were only concerned with tissue donated by living subjects for research and did not refer to the use of postmortem specimens or tissue or organs for transplantation. In addition, all respondents were given the opportunity to ask questions before completing the questionnaire if they were unsure of the meaning of any questions.

We imagine that many of the research fields are interdependent, although the general public may not be aware of this. Our study did not attempt to explain why respondents answered questions in any particular way, but it shows that people may or may not be willing to donate different types of tissue for different types of research. This may be because of a lack of understanding of the clinical and laboratory techniques used in research, but we have not attempted to prove this in our study.

We agree that no explanation was given to respondents (who were not patients) about the benefits of retention of tissue samples; this would have biased the response.

Dr Berney says that our question surrounding consenting for donation of a child's tissue for research is flawed because it does not explain whose child we are discussing. Our pilot study demonstrated that the phrase "your child" eliminated responses from childless adults, adults with children over 16 years of age who were able to consent for themselves, and individuals who had children, but for various reasons were no longer the guardians of such children. The question merely attempted to identify whether or not there was some reluctance by adults to consent for children.

Our research showed a snap shot of public attitudes to tissue donation from living subjects for clinical research and offers no more than an indicator of public attitude, and like most research requires further qualification.

We are grateful to Dr Berney for his comments because they open up the debate on whether the public accepts tissue donation for research purposes. To restore public confidence in the medical profession and research in general, it is crucial for the profession to take account of public perceptions and to understand the nature of the explanations that are required

M L Goodson, B G Vernon School of Population and Health Science, University of Newcastle, Newcastle upon Tyne, NE2 4HH M.L.Goodson@ncl.ac.uk

\section{Limitations of the Wilcoxon matched pairs signed ranks test for comparison studies}

We read the short report by Ellis et al with interest. ${ }^{1}$ However, we are unsure whether they have adequately proved that no significant difference was detected between the two outlined storage methods.

The hypothesis evaluated with the Wilcoxon matched pairs signed ranks test is whether or not the median of the difference scores equals zero. Let us consider the situation of $x$ measurements tending to exceed $y$ measurements in the low range and vice versa in the high range, with similar values in the mid range. Such results may have a median of the difference scores of approximately zero; that is, there might be no significant differences by the Wilcoxon matched pairs signed ranks test, although there would be differences by linear regression (Deming or Passing-Bablok) and/or difference plots.

However, this short report ${ }^{1}$ lacks both a regression equation (proportional and constant error) and difference plots. Therefore, we believe that although the IgG anti-rubella activity in frozen serum stored in primary gel separation tubes may not be significantly different from that stored frozen in secondary tubes, this study did not sufficiently prove this. We recommend, in line with others, ${ }^{2}$ that difference plots ${ }^{3}$ are used for such comparative studies and that such studies are put into a clinical context. ${ }^{34}$

P J Twomey

Department of Clinical Biochemistry, The Ipswich Hospital, Heath Road, Ipswich IP4 5PD, UK taptwomey@aol.com

A Viljoen

Department of Clinical Biochemistry, Royal Infirmary of Edinburgh, Room S6114 Level 2, 51 Little France Crescent, Edinburgh EH16 4SA, UK

\section{References}

1 Ellis V, Charlett A, Bendall R. A comparison of lgG anti-rubella activity in frozen serum stored in primary gel separation tubes or secondary tubes. $J$ Clin Pathol 2004;57:104-6.

2 Hollis S. Analysis of method comparison studies. Ann Clin Biochem 1996:33:1-4.

3 Bland JM, Altman DG. Statistical methods for assessing agreement between two methods of clinical measurement. Lancet 1986;i:307-10.

4 Fraser CG, Kallner A, Kenny D, et al. Introduction: strategies to set global quality specifications in laboratory medicine. Scand J Clin Lab Invest 1999;59:477-8

\section{BOOK REVIEWS}

\section{Basic Pathology: An Introduction to the Mechanisms of Disease}

Lakhani S R, Dilly S A, Finlayson C J, et al. (£22.99.) Arnold, 2003. ISBN 0340810017.

With the new "integrated" undergraduate medical curriculum being adopted by medical schools in many countries, there is an ever increasing need for an appropriate basic pathology textbook. The authors have produced a book which is based on the principles and objectives of the integrated curriculum. Consequently, it is an ideal basic pathology textbook for students in the integrated medical curriculum.

The book has a novel approach to basic pathology, which is different from the standard basic pathology textbooks. There are four parts: "Introduction-what is a disease?", "Defence against disease", "Circulatory disorders", and "Disorders of cell growth". Each part consists of a variable number of chapters containing several unique learning aids.

The material is presented in a format that is easy to read and can be read at leisure. In accordance with the integrated curriculum, some material is presented by using clinical cases-for example, myocardial infarction, breast lump, and prostatic hyperplasia, among others. Innovative additions are the excellent cartoons, selected "key facts", "dictionary box", and "small print". The cartoons are well illustrated, extremely apt, and informative. There is also a selection of relevant tables that complement the text. The inclusion of appropriate colour diagrams, photomicrographs, and macroscopic pathology images aids the text. Clinicopathological case studies are used as a tool to facilitate the integration of pathology with clinical medicine. At the end of each part, there is a selection of questions covering core material with answers and cross references.

There are six colour coded theme maps that cover the four main pathology disciplineshistopathology, haematology, immunology, and microbiology - and two additional overview themes-science and disease and patient and disease.

The authors have produced a remarkable book, which deals with a difficult but important subject in a user friendly manner. The book ought to be prescribed reading for undergraduate students in the new integrated medical curriculum.

D Govender

\section{The Cytology of Soft Tissue Tumours}

Akerman M, Domanski H A. (€110.00.) Karger, 2003. ISBN 380557597.

Åkerman's and Domanski's text The Cytology of Soft Tissue Tumours from the Monographs in Clinical Cytology series is a beautifully illustrated, well referenced and written treatise on the interpretation of fine needle aspirations (FNAs) of these lesions. The text starts with a brief overview of the FNA of soft tissue tumours including accuracy, pitfalls, complications, and a discussion of the aspiration technique itself, with application of ancillary studies. This is followed by a concise review of the specific entities following standard histogenetic organisation. With each major entity, the salient cytological features and differential diagnostic considerations are clearly listed, with comments on the potential pitfalls admixed with helpful hints, providing a practical approach to the diagnosis of the lesions. The final chapter summarises in tabular form the salient diagnostic features and results of ancillary studies of the various entities in groupings based on a pattern recognition approach. Illustrations abound and include air dried May-Grünwald-Giemsa, in addition to alcohol fixed haematoxylin and eosin or occasionally Papanicolaou stained cytological preparations. Little criticism of this text can be found and there is no question that this book should be in the library of those interpreting FNAs of soft tissue lesions.

S Boerner 


\section{CALENDAR OF EVENTS}

Full details of events to be included should be sent to Maggie Butler, Technical Editor JCP. The Cedars, 36 Queen Street, Castle Hedingham, Essex CO9 3HA, UK; email: maggie.butler2@btopenworld.com

\section{Practical Pulmonary Pathology}

27-30 July, 2004, Brompton Hospital, London, UK

Further details: Professor B Corrin, Brompton Hospital, London SW3 6NP, UK. (Tel: +44 (0)20 7351 8420; Fax: +44 (0)20 7351 8293; Email: b.corrin@ic.ac.uk)

\section{ACP Management Course for} Pathologists, 2004

8-10 September 2004, Hardwick Hall Hotel, Sedgefield, County Durham, UK

Further details: V Wood, ACP Central Office, 189 Dyke Road, Hove, East Sussex BN3 ITL, UK. (Tel: +44 (0) 1273 775700; Fax: +44 (0) 1273 773303; Email: Jacqui@pathologists.org.uk)
Combined Adult and Congenital Cardiovascular Pathology Course

8-10 November 2004, Imperial School of Medicine, National Heart and Lung Institute, London, UK

Further details: Short Course Office, National Heart and Lung Institute, Dovehouse Street, London SW3 6LY, UK (Tel: +44 (0)20 7351 8172; Fax: +44 (0)20 7351 8246; Email: shourtcourse.NHLI@ IC.AC.UK)

Asian Pacific Association for Study of the Liver Biennial Conference

11-15 December 2004, New Delhi, India Further details: Dr V Malhotra (General Secretary) or Dr P Sakhuja (Treasurer and Pathology Coordinator), Room 325, Academic Block, Department of Pathology, GB Pant Hospital, New Delhi 110002 India. (Tel: +91 11 23237455; Email: welcome@apaslindia2004.com; Website: www.apaslindia2004.com)

\section{CORRECTIONS}

MUC1 and MUC2 in pancreatic neoplasia. E Levi, D S Klimstra, N V Adsay, A Andrea, O Basturk. J Clin Pathol 2004;

57:456-62. The order of the authors should be E Levi, D S Klimstra, A Andrea, O Basturk, $\mathrm{N}$ V Adsay.

Urinary catecholamines and metabolites in the immediate postoperative period following major surgery. Dr A A Syed, $\mathrm{H}$ A Wheatley, $\mathrm{M} \mathrm{N}$ Badminton, et al. $J$ Clin Pathol 2004;57:548-50. The first author's name should be A A Syed.

Focal nodular hyperplasia with concomitant hepatocellular carcinoma: a case report and clonal analysis. S-H Zhang, W-M Cong, M-C Wu. J Clin Pathol 2004 57:556-9. The image shown in fig 2 should have been fig 3 and vice versa. 